\title{
Renewables exploitation via hydrogen production in gas turbine test facilities: the ZEHTC Project
}

\author{
Maria Alessandra Ancona $^{1 *}$, Michele Bianchi ${ }^{1}$, Lisa Branchini $^{1}$, Francesco Catena ${ }^{1}$, Andrea De Pascale ${ }^{1}$, Francesco \\ Melino $^{1}$, and Antonio Peretto ${ }^{1}$ \\ ${ }^{1}$ Alma Mater Studiorum Università di Bologna, Department of Industrial Engineering (DIN), Viale del Risorgimento 2, 40136 \\ Bologna, Italy
}

\begin{abstract}
In order to pursue the goals of de-carbonization and renewable sources exploitation, an efficient, cost-effective and environmental friendly employment of energy systems is mandatory. In this context, the ERA-Net funded Project ZEHTC (Zero Emission Hydrogen Turbine Center) has been developed, aimed at the realization of a pilot plant consisting in the world first gas turbine test facility making use of the power produced during turbine tests - along with renewables (solar in particular) - for hydrogen production and batteries storage. The produced hydrogen will be locally used to run the gas turbine, thus reducing its environmental impact. The aim of this paper is to present the results of the first steps of the project, consisting in the definition of an optimized grid and in the development of a calculation model for the optimal energy systems design. To this respect, the typology of energy systems to be included into the grid (in addition to the current set-up of the existing turbine test center) will be presented. In addition, the mathematical models specifically developed for each component, as well as the developed operational logic of the entire grid, will be presented and discussed in order to set the optimal size of each systems.
\end{abstract}

\section{Introduction}

The current European Energy Roadmap aims at decreasing the continent's greenhouse gas emissions of a value ranging from $80 \%$ to $95 \%$ by 2050 [1]. Among the several pathways to achieve this goal, a viable solution is to increase the penetration of Renewable Energy Sources (RES) into the electrical system. To their disadvantage, non-programmable RES (i.e. wind and solar) supply electrical power intermittently; thus, as a result of the several hours and even days of electricity surplus and deficit, issues related to the management of local and regional electric grids can occur [2-4]. As a consequence of the increasing share of these sources in the power generation, both long term and seasonal storage capacities are required to ensure a reliable energy supply. In order to increase the contribution of renewables, the hydrogen storage can be considered a solution, being one of the leading options to store energy and looking promising as low-cost option to store electricity over days, weeks or even months [5].

In this context, the aim of this paper is to present the ERA-Net funded Project entitled Zero Emission Hydrogen Turbine Center (ZEHTC) [6], developed by the University of Bologna in collaboration with Siemens
Industrial Turbomachinery (lead partner of the project), Chalmers University of Technology, Linde Industrial Gases, the Municipalty Administrative Authority of Finspång (Sweden) - where the pilot plant goal of the project will be realized - and the County Administrative Board of Östergötland, the regional authority. As will be better described in the following section, the demonstration plant to be realized consists in a smart micro-grid for hydrogen production, storage and reuse within gas turbines, including RES and batteries. In addition, in this paper, the first results of the carried-out analysis will be presented and discussed.

\section{The ZEHTC project}

The Zero Emission Hydrogen Turbine Center (ZEHTC) project [6] is aimed at the realization of a demonstration plant in order to exploit the electrical energy from renewables and from gas turbine testing for hydrogen production. The proposed pilot plant will be realized in Finspång, at the Swedish test facility by Siemens Industrial Turbomachinery, lead partner of the project.

The hydrogen, produced via water electrolysis, will be used locally as a mixture with the turbine fuel gas, i.e. natural gas $(\mathrm{NG})$. As a consequence, both the $\mathrm{NG}$

\footnotetext{
*Corresponding author: maria.ancona2@unibo.it
} 
consumption and the $\mathrm{CO}_{2}$ emissions will be reduced. In addition, the project will also offer the possibility of making further researches and development tests of the low $\mathrm{NO}_{\mathrm{X}}$ turbines with hydrogen fuel. A detailed description of the project aim, the proposed pilot plant and the boundary conditions is given in the next paragraphs.

\subsection{Aim of the project}

The main goals of the project are:

1. de-carbonization of the Finspång turbine test facility by reducing the waste of power, producing hydrogen, installing renewable energy generators and creating a smart micro grid;

2. sharing of knowledge regarding clean energy systems, hybrid solutions, $\mathrm{H}_{2}$ co-firing and micro grids in connection with gas turbines;

3. development of turbines and micro grids towards zero emissions, demonstrating the possibility of de-carbonized island mode solutions;
4. contribution to the development of a sustainable society (regionally and globally).

In order to achieve these objectives, the main contribution of the University of Bologna stands in the development of physical-mathematical models able to simulate the behavior of the realized smart micro grid on the basis of the real boundary conditions. These models will allow $(i)$ to define the optimal size of the energy systems included within the smart grid, (ii) to determine the optimal management strategy of the energy fluxes (with the aim to minimize both the energy waste and the production cost) and (iii) to define the key operational parameters for the predictive diagnostic. All the developed models will be validated on the existing and new energy systems of the equipment.

\subsection{Proposed pilot plant}

The current set-up of the gas turbine test facility by Siemens Industrial Turbomachinery in Finspång and the proposed pilot plant are shown in Figure 1.

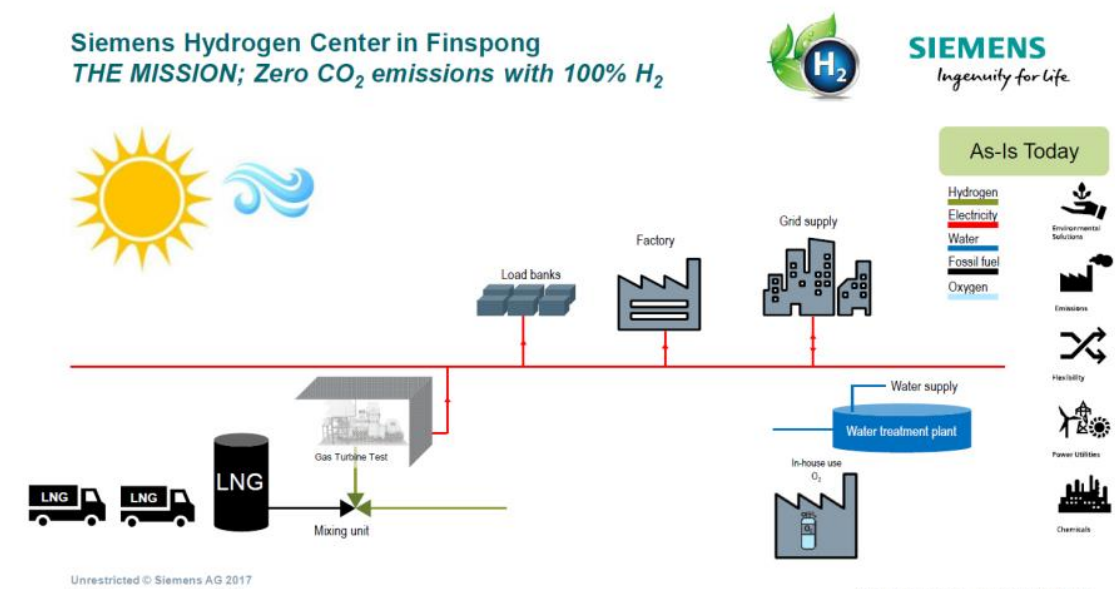

a)
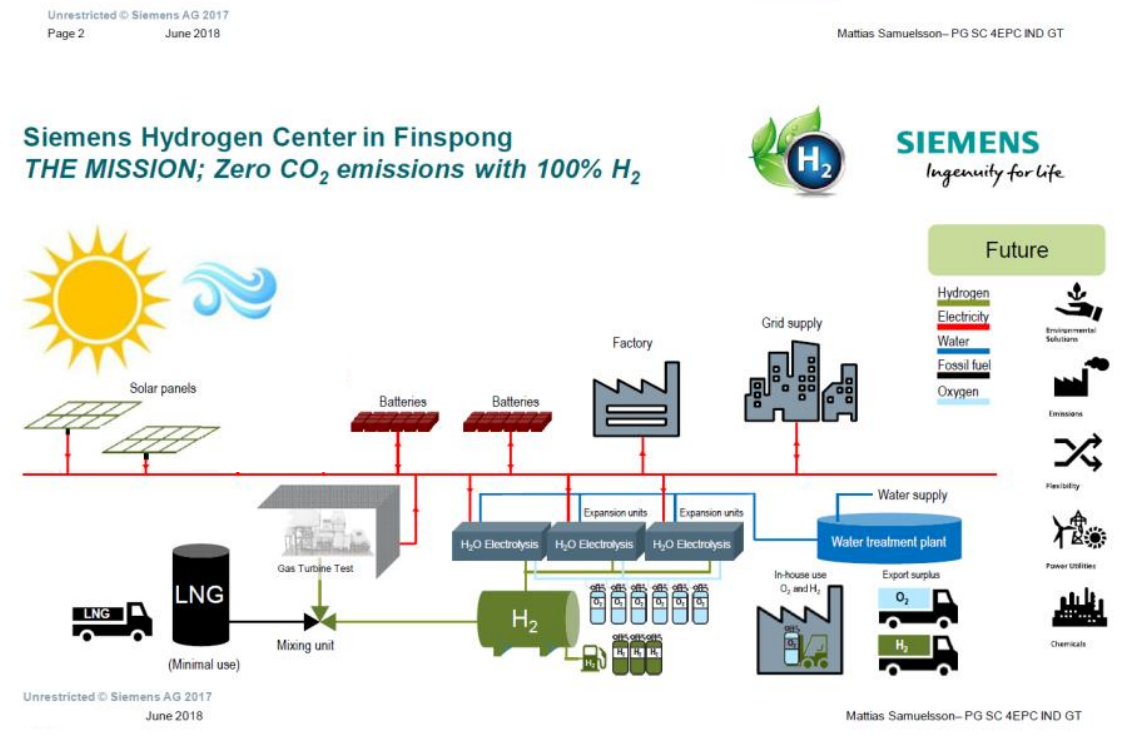

b)

Fig. 1. a) current set-up of the test facility; b) pilot plant set-up of the ZEHTC project [6].

At present (Figure 1a), since the facility site has no connection with a NG distribution network, the fuel required for the gas turbines tests is provided as Liquefied Natural Gas (LNG) via trucks. Considering that the facility tests GTs up to $60 \mathrm{MW}$ of produced power, the LNG supply operation is frequent and, thus, onerous from an environmental viewpoint. In addition, the connection with the local electricity grid is limited to $15 \mathrm{MW}$. Consequently, the produced power is partly sold to the grid, but the most is dissipated in load banks.

In order to use this power in a more effective way and to decarbonize the test facility, the pilot plant shown 
in Figure $1 \mathrm{~b}$ has been conceived. In detail, the following energy systems will be added to the facility in order to create the micro-grid: (1) photovoltaic (PV) panels, to produce electricity from renewables as integration to the GT produced power; (2) an electrolyzer, to exploit the electricity for hydrogen production; (3) a storage system, coupled with a compressor, for the produced hydrogen and (4) batteries to store the eventual excess of power not fed to the electrolyzer. The produced hydrogen will be then used, mixed with the NG, to run the gas turbines tests. To this respect, the reduced use of natural gas will lead to reduced transportations as well as transport emissions. Furthermore, the local use of hydrogen will reduce the turbine exhaust emissions, being a green fuel with no $\mathrm{CO}$ or $\mathrm{CO}_{2}$ emissions.

Based on the described characteristics, it will become the world first GT test facility making use of power produced during turbine tests for $\mathrm{H}_{2}$ production and charging of batteries, reusing both the hydrogen and the electricity locally. Consequently, the system will be a micro grid similar to an electrical island operation.

\subsection{Boundary conditions}

In order to optimize the size of the energy systems to be added to the current plant set-up, the following boundary conditions have to be considered:

- the planned tests with a mixture of hydrogen and NG will be carried out on a GT with a size equal to $35 \mathrm{MW}$;

- 32 weeks of tests have been planned, with an estimated tests duration of $2 \mathrm{~h} /$ week $(1 \mathrm{~h} /$ day for two consecutive days);

- in a first phase, it is supposed to run the GT in design operation during all the tests;

- the $\mathrm{H}_{2}$ content in the mixture will be equal to the $15 \%$ (volume based), corresponding to $250 \mathrm{~kg}$ of hydrogen consumed per test (i.e. $125 \mathrm{~kg} / \mathrm{h}$ )

In addition, the PV non-dimensional production profile during the year, for the considered site, is shown in Figure 2.

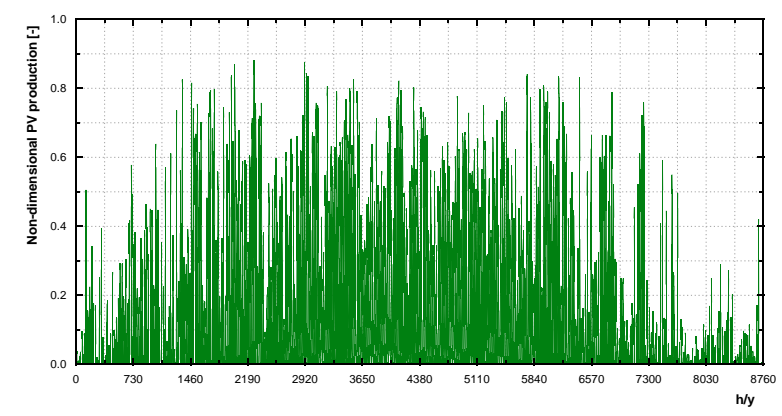

Fig. 2. Non-dimensional electrical PV panels production for the considered site, as a function of the hours during the year.

\section{Calculation model and assumptions}

In order to define the optimal design of the micro-grid, the analysis of the plant has been performed with a specifically developed calculation model. In more detail, Figure 3 shows the flow chart of the implemented code. The main inputs of the code are the PV and the GT production profiles, besides the operating parameters of each component. After the inputs' definition, for each time step the calculation starts following the developed routine:

- evaluation of the available electric power, given by the sum of the electric power produced by the PV panels and by the GT;

- evaluation of the electrolyzer electrical consumption (hypothesis of design operation in this first phase of the project);

- evaluation of the produced and consumed $\mathrm{H}_{2}$ and estimation of the storage mass variation;

- evaluation of the storage pressure: if the calculated pressure is higher than the minimum acceptable pressure, then the final mass within the storage tank is evaluated; otherwise, the hydrogen admissible consumption is recalculated and the storage pressure is evaluated again.

After this first step, the routine moves to the compressor:

- evaluation of the compressor pressure ratio;

- calculation of the compressor electric power consumption;

- calculation of the available electric power: if it is enough to move both the electrolyzer and the compressor, then the residual electric power and the possibility of charging the batteries are evaluated; otherwise, the missing electric power is evaluated and the batteries initial condition is assessed: ( $i$ ) if the batteries can supply the missing electric power, then no power waste occurs; (ii) if the batteries cannot supply the missing electric power, then the electrolyzer and the compressor are shut down.

As a consequence, for each analyzed time step the developed code allows to evaluate:

- the available electric power from PV and GT;

- the input electric power of the electrolyzer and of the compressor;

- $\quad$ the mass flow rate of produced $\mathrm{H}_{2}$;

- the pressure of the storage tank;

- the residual electric power;

- the initial and final condition of the batteries;

- the wasted electric power;

- the mass flow rate of $\mathrm{H}_{2}$ to the GT.

\section{Components model description}

In order to define an optimized grid and to develop a tool for the optimal energy systems design, for each component of the grid (PV panels, electrolyzer, batteries, compressor and hydrogen storage), literature and specific calculation models have been used.

\subsection{PV panels}

The PV panel performance are mainly affected by the solar radiation and the cell temperature, in addition to the operating voltage and the electric current. The model employed to simulate the PV panel behavior is presented in [7]. 


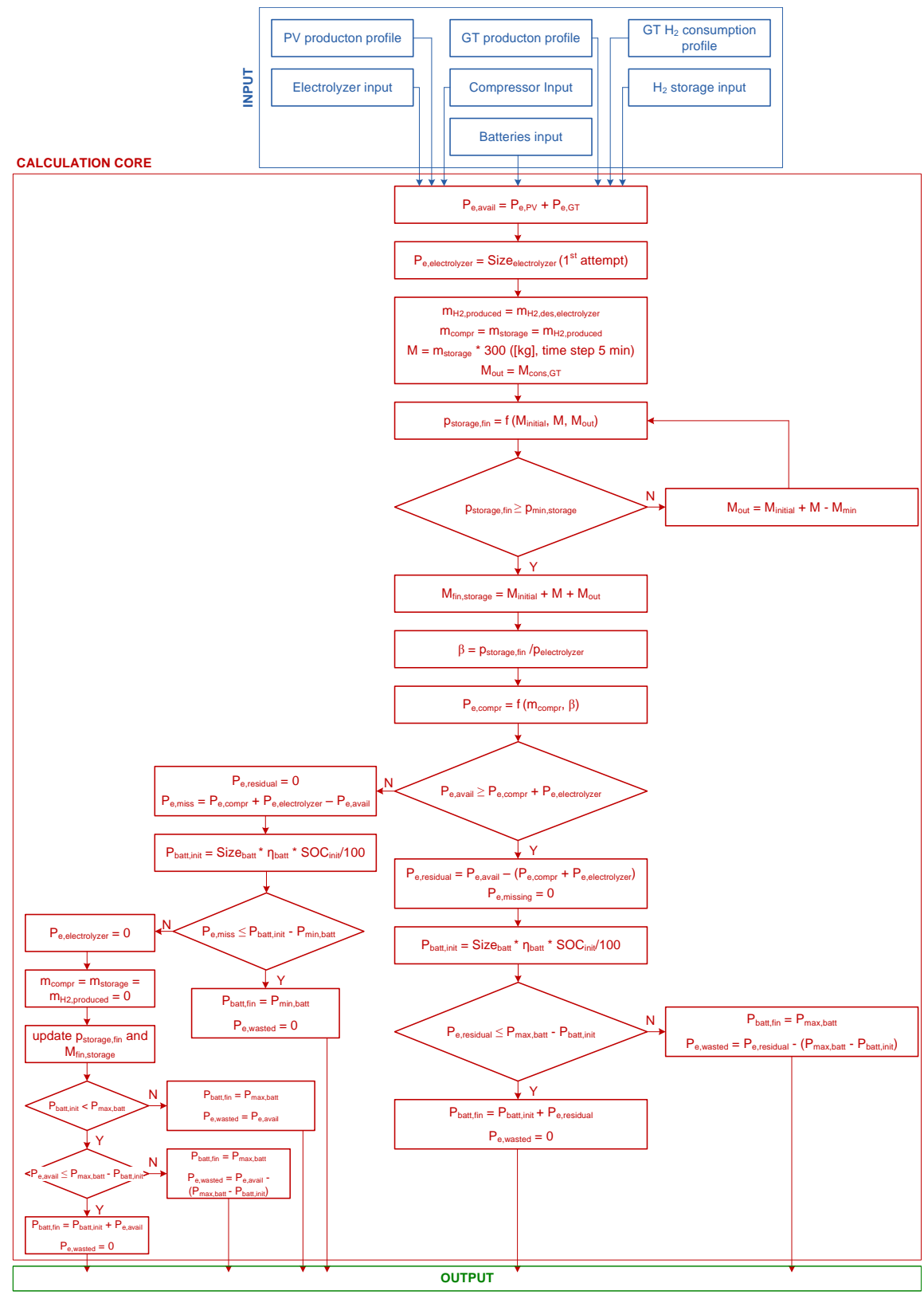

Fig. 3. Flow chart of the calculation model.

The aim of the model is to obtain the connection between the produced electric current $\left(I_{P V}\right)$ and the operating voltage $\left(V_{P V}\right)$, described by the Eq. (1):

$I_{P V}=I_{L}-I_{0}\left[\exp \left(\frac{V_{P V}+R_{s} I_{P V}}{V_{t} a}\right)-1\right]-\frac{V_{P V}+R_{S} I_{P V}}{R_{p}}$

where $I_{L}[\mathrm{~A}]$ is the photovoltaic current produced by the incident light, $I_{0}[\mathrm{~A}]$ is the diode saturation current, $V_{t}$ [V] is the thermal voltage, $a[-]$ is the diode constant, $R_{s}[\Omega]$ is the equivalent series resistance and $R_{p}[\Omega]$ is the equivalent parallel resistance.

Before solving the Eq. (1), $R_{s}$ and $R_{p}$ must be determined for the specific PV panel. As reported in [7], their values can be obtained by an iterative method, in which the maximum generated power of the PV panel, computed by means of the model, is compared to the maximum generated power shown in the datasheet. Finally, once determined $R_{s}$ and $R_{p}$, the characteristic
$I_{P V}-V_{P V}$ curve can be computed solving the Eq. (1), by means of an iterative procedure.

Derived the $I_{P V}-V_{P V}$ curves for the selected solar module, it is possible to predict the generated power $\left(P_{P V}\right)$ and the instantaneous solar module efficiency $\left(\eta_{P V}\right)$, defined by the ratio between the energy produced by the PV panels $\left(E_{P V}\right)$ and the solar energy incident on its surface $\left(E_{R R}\right)$ :

$\eta_{P V}=\frac{E_{P V}}{E_{R R}}=\frac{\int_{0}^{t} P_{P V} d t}{\int_{0}^{t} P_{R R} d t}=\frac{\int_{0}^{t} P_{P V} d t}{\int_{0}^{t} R R \cdot S_{P V} d t}$

where $R R\left[\mathrm{~W} / \mathrm{m}^{2}\right]$ is the solar radiation and $S_{P V}\left[\mathrm{~m}^{2}\right]$ is the module surface.

\subsection{Electrolyzer}

The electrolyzer behavior can be simulated by the mathematical model developed in [8]. In more detail, the 
model describes the electrochemical behavior of the cell by means of the electric potential calculation $\left(E_{\text {cell }}[\mathrm{V}]\right)$ :

$E_{c e l l}=E_{\text {rev }}+E_{a c t, a}+E_{a c t, c}+E_{o h m}$

where $E_{\text {rev }}[\mathrm{V}]$ is the reversible potential of the cell, $E_{a c t, a}[\mathrm{~V}]$ is the anode activation potential, $E_{a c t, c}[\mathrm{~V}]$ is the cathode activation potential and $E_{\text {ohm }}[\mathrm{V}]$ is the ohmic potential. The term $E_{\text {rev }}$ represents the minimum electric potential required at the equilibrium and it can be described by the Nernst equation:

$E_{\text {rev }}=E_{\text {rev }}^{0}+\frac{R T}{2 F} \ln \left[\frac{1.5\left(p-p_{H 2 O}\right)}{p_{H 2 O}}\right]$

where $\quad E_{\text {rev }}^{0}=1.50342-9.956 \cdot 10^{-4} \cdot T+2.5 \cdot T^{2}$ [V] is the reversible potential of the cell in standard conditions, $T[\mathrm{~K}]$ is the operating temperature of the electrolyzer, $R[\mathrm{~J} / \mathrm{mol} \cdot \mathrm{K}]$ is the gas constant, $F[\mathrm{C} / \mathrm{mol}]$ is the Faraday constant, $p[\mathrm{~Pa}]$ is the operating pressure of the electrolyzer and $p_{\mathrm{H} 2 \mathrm{O}}[\mathrm{Pa}]$ is the water partial pressure.

The activation potentials, which account for the electrochemical kinetics of the reaction, can be deduced by the following equation:

$E_{a c t, k}=\frac{R T}{F} \sinh ^{-1}\left(\frac{J}{2 J_{0, k}}\right) \quad k=$ anode, cathode

where $J\left[\mathrm{~A} / \mathrm{cm}^{2}\right]$ is the current density in input to the electrolyzer and $J_{0, k}\left[\mathrm{~A} / \mathrm{cm}^{2}\right]$ is the exchange current density.

Finally, the ohmic potential is caused by ionic losses mainly in the membrane and can be expressed as:

$E_{\text {ohm }}=J \cdot R_{E}$

where $R_{E}\left[\Omega \cdot \mathrm{cm}^{2}\right]$ is the internal resistance of the electrolyzer.

The efficiency of the electrolyzer $\left(\eta_{E}\right)$ is defined as

$\eta_{E}=\frac{\dot{n}_{H 2} \cdot H H V_{H 2}}{P_{E \text { in }}}$

where $\dot{n}_{H 2}[\mathrm{~mol} / \mathrm{s}]$ is the molar flow rate of the produced $\mathrm{H}_{2}, H H V_{H 2}[\mathrm{~J} / \mathrm{kg}]$ is the hydrogen higher heating value and $P_{E, \text { in }}[\mathrm{W}]$ is the input power of the electrolyzer.

\subsection{Batteries}

The battery charge and discharge processes can be described by the semi-empirical model reported in [9], representing accurately the voltage dynamics when the electric current varies and considering the voltage as a function of the State of Charge (SOC), which is correlated to the battery capacity. Since in [9] energy losses are not considered, the model has been improved by the implementation of the charge/discharge efficiency: on the basis of [10,11], all the losses of the charge and discharge processes have been attributed to the charge phase. As a consequence, it is assumed that the discharge process does not present losses, while the charge efficiency $\left(\eta_{\text {charge }}\right)$ is expressed by: $\eta_{\text {charge }}(t)=1-\exp \left[\left(\frac{20.73}{\frac{i(t)_{\text {batt }}}{i_{\mathrm{C} 10}+0.55}}\right) \cdot(\operatorname{SOC}(t)-1)\right]$

where $i_{\text {batt }}[\mathrm{A}]$ is the input current of the battery and $i_{C 10}[\mathrm{~A}]$ is the current that allows to discharge the battery in 10 hours. On the basis of the assumptions above, the actual electric power available from the battery $\left(P_{b a t t}\right.$ [W]) can be expressed as:

$P_{\text {batt }}=P_{\text {batt }, c h} \cdot \eta_{\text {charge }}$

where $P_{b a t t, c h}[\mathrm{~W}]$ is the electric power in input to the battery during the charge process.

\subsection{Compressor}

The compressor behaviour has been simulated through the evaluation of the total efficiency $\left(\eta_{t o t}\right)$, defined as:

$\eta_{\text {tot }}={ }^{P_{i d}} / P_{\text {el }}$

where $P_{i d}[\mathrm{~kW}]$ is the ideal power and $P_{e l}[\mathrm{~kW}]$ is the actual electric power. In detail, several compressor ratio $(\beta)$ values have been examined, in order to obtain the behaviour curves of the compressor. In Figure 4 the polynomial curves of the electric power as a function of the mass flow rate are shown, in a dimensionless form with respect to the starting point conditions.

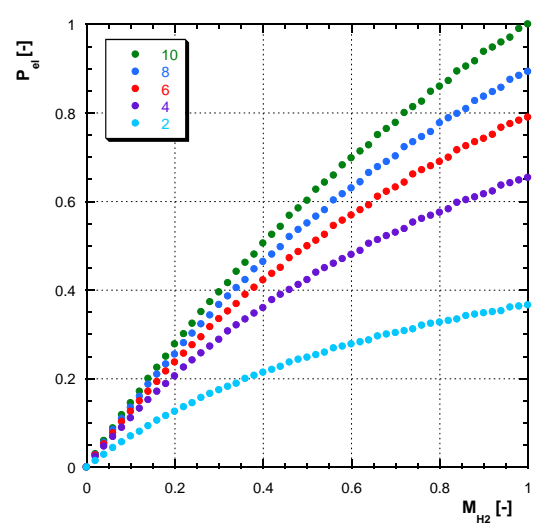

Fig. 4. Normalized electric power as a function of the normalized mass flow rate for several $\beta$ values.

\subsection{Hydrogen storage}

The pressure within the storage tank has been evaluated on the basis of the mass flow of hydrogen from the electrolyzer. The first step in order to model the storage tank is the definition of the minimum and maximum capacities; in particular, the minimum pressure $\left(p_{\text {min }}\right)$ and stored mass $\left(M_{\min }\right)$ have been defined on the basis of the electrolyzer output, while the maximum pressure $\left(p_{\max }\right)$ and stored mass $\left(M_{\max }\right)$ have been defined on the basis of the project boundary conditions. Therefore, the tank volume $\left(V_{\text {tank }}\right)$ is calculated as:

$V_{\text {tank }}=M_{\max } / \rho$ 
where $\rho\left[\mathrm{kg} / \mathrm{m}^{3}\right]$ is the $\mathrm{H}_{2}$ density at the maximum pressure.

The calculation of the final conditions in the storage tank starts with the final mass evaluation $\left(M_{f i n}\right)$ :

$M_{\text {fin }}=M_{\text {initial }}+M_{\text {inlet }}-M_{\text {outlet }}$

where $M_{\text {initial }}[\mathrm{kg}]$ is the mass already stored in the tank, $M_{\text {inlet }}[\mathrm{kg}]$ is the mass at the inlet of the tank (i.e. at the outlet of the electrolyzer) and $M_{\text {outlet }}[\mathrm{kg}]$ is the mass at the outlet of the tank (i.e. at the inlet of the GT). Once $M_{\text {fin }}$ has been calculated, the final conditions (specific volume and pressure) are evaluated.

\section{Preliminary results}

In order to figure out the behavior of the realized smart micro grid on the basis of real boundary conditions, a preliminary parametric analysis has been carried out. The starting conditions of the several components have been defined on the basis of the boundary conditions of the project:

- PV panels size: $300 \mathrm{~kW}$;

- electrolyzer size and nominal efficiency: 225 $\mathrm{kW}$ and $74 \%$;

- compressor size: $23 \mathrm{~kW}$;

- $\mathrm{H}_{2}$ storage pressure: 300 bar;

In this preliminary analysis, the hydrogen produced during the year has been investigated, varying the electrolyzer size and the battery storage capacity; in particular, the electrolyzer size has been varied between $100 \mathrm{~kW}$ and $325 \mathrm{~kW}$, while 3 different battery capacities $(35,70$ and $150 \mathrm{kWh})$ have been examined. The results of this preliminary analysis are shown in Figure 5.

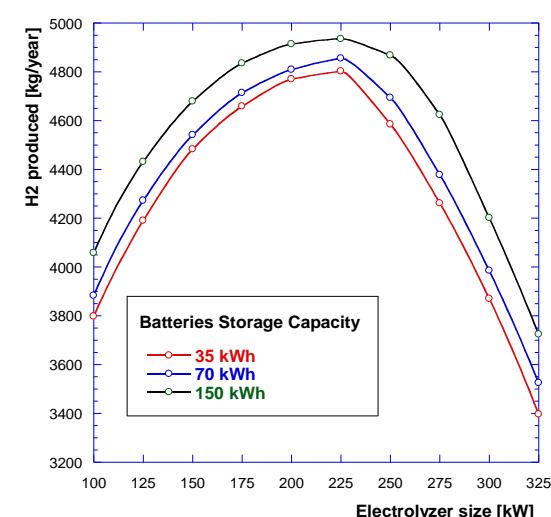

Fig. 5. $\mathrm{H}_{2}$ produced during the year, as a function of the electrolyzer size for several battery storage capacities.

First of all, the battery capacity influences the hydrogen production: the higher the battery capacity, the higher the hydrogen production. Indeed, the batteries are used when the available electric power is not enough to move both the electrolyzer and the compressor; thus, a higher capacity of the batteries allows to store a higher amount of electric energy during the year and then to supply a greater amount of electric power to the compressor and the electrolyzer that, otherwise, would be shut down. In the second instance, the optimal electrolyzer size is $225 \mathrm{~kW}$ for all the analyzed battery capacities; indeed, the maximum hydrogen production is equal to about $4950 \mathrm{~kg} / \mathrm{year}$ for an electrolyzer size of $225 \mathrm{~kW}$ and a battery capacity of $150 \mathrm{kWh}$.

\section{Concluding Remarks}

The aim of this paper is to present the ERA-Net funded Project ZEHTC, aimed at the realization of a pilot plant consisting in the world first gas turbine test facility making use of the power produced during turbine tests - along with renewables (solar) - for $\mathrm{H}_{2}$ production and batteries storage. The results of the first steps of the project consist in the definition of an optimized grid and in the development of a calculation model for the optimal energy systems design based on literature models for the components and on specifically developed operational logics. Preliminary investigations carried-out by applying the calculation model to the micro-grid allow to set the starting point, in terms of components' size, for the proper pilot plant design.

This work was supported by the ERA-Net funded Project "ZEHTC (Zero Emission Hydrogen Turbine Center", Smart Energy Systems Call 2018.

\section{References}

1. Innovative large-scale energy storage technologies and Power-to-Gas concepts after optimization Roadmap for large-scale storage based $\mathrm{PtG}$ conversion in the EU up to 2050. Available at: https://www.storeandgo.info/publications/otherpublications/ (2019)

2. M. Karimi, H. Mokhlis, K. Naidu, S. Uddin, A.H.A. Bakar, Renew Sust Energ Rev, 53, 594-605 (2016)

3. M.A. Eltawil, Z. Zhao, Renew Sust Energ Rev, 14, 1 (2010)

4. C. Jung, D. Taubert, D. Schindler, Energy Conversion and Management, 188, 462-472 (2019)

5. Report IEA, The Future of Hydrogen, Available at: https://www.iea.org/hydrogen2019 (2019)

6. ZEHTC project. Available at: https://www.eralearn.eu/network-information/networks/ensgplusregsys/1st-regsys-joint-call-2018/zeroemission-hydrogen-turbine-center

7. M.G. Villalva, J.R. Gazoli, E. Ruppert Filho, IEEE Transactions on Power Electronics, 24, 5 (2009)

8. M. Ni, M.K. Leung, D.Y. Leung, Energy Conversion and Management, 49, 10 (2008)

9. O. Tremblay, L.A. Dessaint, World Electric Vehicle Journal, 3, 2 (2009)

10. E.M.G. Rodrigues, R. Godina, J.P.S. Catalão, Applied Energy, 188, 315-329 (2017)

11. J.B. Copetti, E. Lorenzo, F. Chenlo, Progr Photovolt: research and applications, 1, 4 (1993) 